\title{
Pengembangan Inovasi Pembelajaran Berbasis Proyek Ilmiah dalam Meningkatkan Sikap terhadap Ilmu Pengetahuan Siswa SMP Kota Malang
}

\author{
Novi Anisa Hidayati ${ }^{1}$, Nata Hendriati ${ }^{1}$, Puguh Prasetyo ${ }^{1}$, Hendryani A. Putri ${ }^{2} \&$ Siti \\ Maimunah $^{1}$ \\ ${ }^{1}$ Fakultas Psikologi, Universitas Muhammadiyah Malang \\ ${ }^{2}$ Fakultas Keguruan dan ilmu Pendidikan, Universitas Muhammadiyah Malang \\ $\doteq$ e-mail:novianisahidayati@gmail.com
}

\begin{abstract}
Abstrak
One of Indonesian national education goals is to educate the intellectual life of the nation which is embodied in the preamble of the 1945 Constitution.Education plays a very central role to facilitate students to prepare the demandsof science and technology advancement in the $21^{\text {st }}$ century. To achieve these goals, education requires a powerful learning method which can improve the positive attitude toward science of student from an early age. This study aims to determine the differences in attitude toward science between students in experimental group who received projects based learning and students who become the control group. This was quasy experimental research with Pretest-Posttest Control Group Design. The populations were VIII graders in Malang city. The sampling was 54 students selected using purposive sampling. Instruments were validated by expert and tried out. The reliability coefficients for attitude toward science scale was 0,954.The results showed that attitude toward science students in experimental group who received projects based learning has significant difference withstudents in control group.
\end{abstract}

Kata Kunci: project based learning, attitude toward science, middle school student

Copyright (C) 2017 IICET (Indonesia) - All Rights Reserved

Indonesian Institute for Counseling, Education and Therapy (IICET)

\section{PENDAHULUAN}

Kemajuan Ilmu Pengetahuan dan Teknologi (IPTEK) saat ini layaknya kebutuhan primer yang terus digali oleh banyak negara maju dan berkembang. Hal ini tampak pada aktivitas penelitian para ilmuwan di berbagai belahan dunia serta upaya publikasi hasil penelitian dalam jurnal ilmiah internasional. Berdasarkan situs SCImago Journal \& Country Rank, sebuah portal database jurnal ilmiah internasional dari Scopus, Indonesia berada di peringkat ke-57 di dunia dalam peringkat publikasi jurnal ilmiah terhitung dari tahun 1996 hingga tahun 2015. Peringkat ini sangat jauh dibanding dengan negara tetangga seperti China yang berada di peringkat kedua setelah Amerika. Dalam dekade terakhir ini, China mengalami peningkatan pesat dalam menghasilkan penelitian hingga mencapai lima kali lipat tiap tahunnya. Berdasarkan indeks Scopus tersebut menunjukkan bahwa prestasi Indonesia masih jauh tertinggal dalam penelitian dan pengembangan ilmu pengetahuan. Studi sebelumnya memaparkan bahwa prestasi dalam ilmu pengetahuan sangat dipengaruhi oleh adanya sikap positif terhadap ilmu pengetahuan (attitude toward science) (Osborne et al, 2003; Papanastasiou \& Zembylas, 2004; Narmadha\& Chamundeswari, 2013; Dosanjh, 2015).

Sikap terhadap ilmu pengetahuan (attitude toward science) adalah seperangkat perilaku afektif terhadap ilmu pengetahuan yang berisi aspek sikap yang senang terhadap ilmu pengetahuan dan profesi ilmuwan, menikmati pengalaman belajar ilmu pengetahuan, bersikap ilmiah, penyelidikan ilmiah, berkembangnya minat dalam berkarir di bidang ilmu pengetahuan dan aktivitas yang berkaitan dengannya (Klopfer, 1971). 
Faris (2008) dalam penelitiannya memaparkan bahwa sikap negatif siswa terhadap ilmu pengetahuandan matematika merupakan ancaman yang serius bagi kesejahteraan negara di masa depan.

Sebagaimana misi pendidikan Indonesia yang termaktub dalam pembukaan Undang Undang Dasar (UUD) 1945 yakni misi mencerdaskan kehidupan bangsa. Bangsa yang terlepas dari penjajahan, terentas dari kebodohan dan menjadi bangsa yang bermartabat dan mampu bersaing dengan negara maju dalam penelitian dan kemajuan IPTEK. Guna mencapai tujuan tersebut, pendidikan memerlukan metode pembelajaran yang ampuh dalam mengembangkan potensi anak bangsa untuk mencintai sains dan berprestasi dalam kemajuan ilmu pengetahuan melalui peningkatan sikap terhadap ilmi pengetahuan (sains).

Pembelajaran berbasis proyek (project based learning) merupakan salah satu metode pembelajaran yang menerapkan paradigma konstruktivisme dari tokoh Psikologi Pendidikan Jean Piaget yakni memandang belajar sebagai proses membangun pengetahuan oleh pelajar itu sendiri, bukan peran pasif pemindahan informasi dari guru kepada siswa. Blumenfeld et al (1991) menemukan bahwa pemberian pendidikan berbasis proyek (project based learning) pada siswa dapat lebih meningkatkan sikap dan motivasi belajar karena proses pemahaman pengetahuan berasal dari pengalaman siswa itu sendiri.Studi sebelumnya di Hamza School oleh Faris (2008) didapatkan hasil bahwa sebanyak 22 siswa dari 25 siswa kelas IXyang berpartisipasi dalam kegiatan project based learning menunjukkan sikap belajar sains yang tergolong tinggi dan mampu bekerja dalam tim. Siswa termotivasi untuk merancang investigasi dengan caranya sendiri dan mewujudkan hasil investigasi lewat produk proyek ilmiah. Pengembangan metode pembelajaran berbasis proyek ilmiah ini diharapkan mampu meningkatkan sikap positif siswa terhadap ilmu pengetahuan di sekolah. Harapannya, sejak dini siswa mampu berorientasi pada proyek ilmiah dan menghasilkan karya ilmiah sebagai produk akhir pembelajaran. Hal ini bertujuan membangun karakter ilmuwan pada siswa guna mendorong kemajuan IPTEK Indonesia untuk bersaing dengan berbagai negara di kancah internasional.

Berdasarkan uraian di atas, rumusan masalah dalam penelitian ini adalah apakah terdapat perbedaan peningkatan sikap terhadap ilmu pengetahuan (attitude toward science) antara siswa SMP yang mendapat pembelajaran scientific project based learning dengan siswa SMP yang menjadi kelompok kontrol?Tujuan dari penelitian ini adalah untuk mengetahui perbedaan peningkatan sikap terhadap ilmu pengetahuan (attitude toward science) antara siswa SMP yang mendapat pembelajaran scientific project based learning dengan siswa SMP yang menjadi kelompok kontrol.

\section{METODOLOGI}

Penelitian ini merupakan penelitian eksperimen quasi dengan desain penelitian pretest-posttest control group design. Penelitian dilaksanakan di SMPN 17 Malang pada semester genap tahun ajaran 2016/2017 selama 6 minggu. Populasi merupakan seluruh siswa kelas VIII SMP Negeri 17 Malang sebanyak 216 siswa.Pengumpulan data diawali dengan pengambilan sampel secara purposive samplingsebanyak 54 partisipan siswa kelas VIII SMP Negeri 17 Malang. Partisipan diminta kesediaan untuk mengisi biodata dan informed consent kemudian mengerjakanpretest untuk mengukur sikap awal terhadap sains. Partisipan sebanyak 54 tersebut selanjutnya dibentuk 2 kelas dengan jumlah yang sama untuk dimasukkan ke dalam kelas kontrol dan kelas eksperimen. Kelas eksperimen (E) sebanyak 27 siswa mendapatkan perlakuan berupa pembelajaran berbasis proyek ilmiah, dan kelas kontrol (K) sebanyak 27 siswatidak mendapat perlakuan pembelajaran berbasis proyek ilmiah.

Instrumen yang digunakan terdiri dari instrumen pengukuran daninstrumen perlakuan. Instrumen pengukuran atau pretest-posttestyang digunakan adalah instrumen skala milik Klopfer (1971) yang berjuduITOSRA (Test of Science RelatedAttitudes)atau tes penilaian sikap terhadap sains. Sebelum instrumen digunakan telah dilakukan uji validitas dan reliabilitas item skala pada 30 siswa SMP kelas VIII Kota Malang yang kemudian dianalisis dengan menggunakan program SPSS 22 for windows. Dari sebanyak 70 item yang diujikan terdapat 23 item memiliki nilai pearson correlation kurang dari nilai $r$ tabel 0,361 sehingga item-item tersebut dinyatakan gugur dan tidak valid. Sedangkan 47 item yang lain dapat dikatakan valid.Uji reliabilitas menggunakan uji reliabilitas Cronbach's Alphadiperoleh nilai Cronbach's Alpha sebesar 0,954, atau lebih besar dari 0,6. Sehingga dapat dikatakan bahwa instrumen penelitian tersebut reliabel.

Instrumen perlakuan kelas eksperimen terdiri dari materi proyek ilmiahdancontoh produk proyek ilmiah pendukung pembelajaran berbasis proyek ilmiah. Terdapat tiga tahapan dalam pemberian pembelajaran berbasis proyek ilmiah, yakni (1) Introducing science project; mengenalkan proyek ilmiah pada siswa melalui 
salah satumateri pelajaran IPA(contoh: bab alat optik) dengan memberi pertanyaan mendasar tentang bagaimana cara kerja alat optik lewat proyek pembuatan alat optik, (2) Design A Plan; penugasankepada siswa untuk merancang dan melakukan penyelidikan mengenai permasalahan disekitarnya, (3) Monitoring progress; melakukan monitor dan bimbingan pada siswa dalam penugasan proyek ilmiah (4) Assess the outcome; mengevaluasi dan memberi feedback pada hasil presentasi proyek ilmiah siswa, (5) Science Fair;siswa mempresentasikan hasil proyek ilmiah yang telah dibuat kepada publik.

Setelah kelas eksperimen mengikuti tahapanperlakuan pembelajaran berbasis proyek ilmiah dan kelas kontrol tidak mendapatkan pembelajaran berbasis proyek ilmiah, selanjutnyaseluruh partisipan sebanyak 54 siswa mengerjakanpostest untuk mengukur sikap akhir terhadap sains. Hasil pretest dan postest tersebut kemudian dianalisis menggunakan program SPSS 22 for windows.

\section{HASIL DAN PEMBAHASAN}

Guna mengetahui besarnya peningkatan sikap siswa terhadap ilmu pengetahuan (sains), dilakukan analisis pada data pretest dan posttest sehingga mendapatkan data gain. Menurut Hake (1999) perhitungan rumus indeks gain ternormalisasi $(g)$ yaitu:

$$
g=\frac{\text { posttest score }- \text { pretest score }}{\text { maximumpossible score }- \text { pretest score }}
$$

Dengan menggunakan data indeks gain, dilakukan ujiprasyarat analisis sebelum dilakukan uji hipotesis penelitian. Uji prasyarat analisis meliputi uji normalitas dan homogenitas varians. Uji normalitas menggunakan metode Kolmogorov-Smirnov untuk menentukan apakah data yang digunakan berdistribusi normal atau tidak (Tabel 1). Dasar pengambilan keputusan dari uji ini yaitu dengan menggunakan nilai signifikan ( $p$-value). Nilai signifikansi hasi pengujian yang lebih besar dari alpha sebesar 5\% menunjukkan bahwa data yang digunakan berdistribusi normal.Berdasarkan Tabel 1 didapatkan nilai signifikansi ( $p$-value) uji Kolmogorov-Smirnov sikap siswa terhadap sains pada kelas eksperimen dan kelas kontrol lebih besar dari 0,05 sehingga setiap data berdistribusi normal.

Uji homogenitas menggunakan metode Levene untuk mengetahui apakah varians-varians dari populasi tersebut homogen atau heterogen (Tabel 2). Dasar pengambilan keputusan uji ini adalah dengan menggunakan nilai signifikansi ( $p$-value). Nilai signifikansi hasil pengujian yang lebih besar dari alpha sebesar $5 \%$ menunjukkan bahwa masing-masing data kelas kontrol dan eksperimenmemiliki varians yang sama.Berdasarkan Tabel 2 didapatkan nilai signifikansi ( $p$-value) sikap siswa terhadap sains lebih besar dari 0,05 sehingga ragam antara kelas eksperimen dan kelas kontrol adalah sama atau homogen.

Tabel 1. Uji Normalitas Data

\begin{tabular}{ccccc}
\hline Populasi & Kelas & Jumlah Siswa & p-value & Keterangan \\
\hline SMPN 17 & Kontrol & 27 & 0,507 & Normal \\
& Eksperimen & 27 & 0,226 & Normal
\end{tabular}

Tabel 2. Uji Homogenitas Varians

\begin{tabular}{ccccc}
\hline Populasi & Kelas & Levene Statistics & p-value & Keterangan \\
\hline SMPN 17 & Kontrol & 0,292 & 0,591 & Homogen \\
& Eksperimen & & & \\
\hline
\end{tabular}

Tabel 3. Uji Hipotesis

\begin{tabular}{cccccc}
\hline Populasi & Kelas & Rata-rata & $t$ & p-value & Keterangan \\
\hline SMPN 17 & Kontrol & $-0,49858$ & $-7,703$ & 0,000 & Ada perbedaan \\
& Eksperimen & 0,15310 & & \\
\hline
\end{tabular}


Setelah data indeks gain memenuhi uji asumsi normalitas dan homogenitas, maka dilakukan uji hipotesis pada data gain kelas kontrol dan ekperimen dengan menggunakan uji independent $t$.Berdasarkan Tabel 3 dapat diketahui nilai pvalue pada kelas kontrol dan eksperimen untuk SMPN 17 sebesar 0,000 atau lebih besar dari 0,05 sehingga dapat disimpulkan bahwa terdapat perbedaan sikap terhadap sains pada kelas kontrol dan eksperimensetelah mendapatkan inovasi pembelajaran berbasis proyek ilmiah.

Berdasarkan Tabel 3 dapat diketahui bahwa rata-rata data gain kelas eksperimen adalah sebesar 0,1531.Untuk mengetahui secara spesifik indikator yang mengalami peningkatan secara signifikan, dilakukan analisis deskriptif dengan menggunakan chart sebagai berikut.

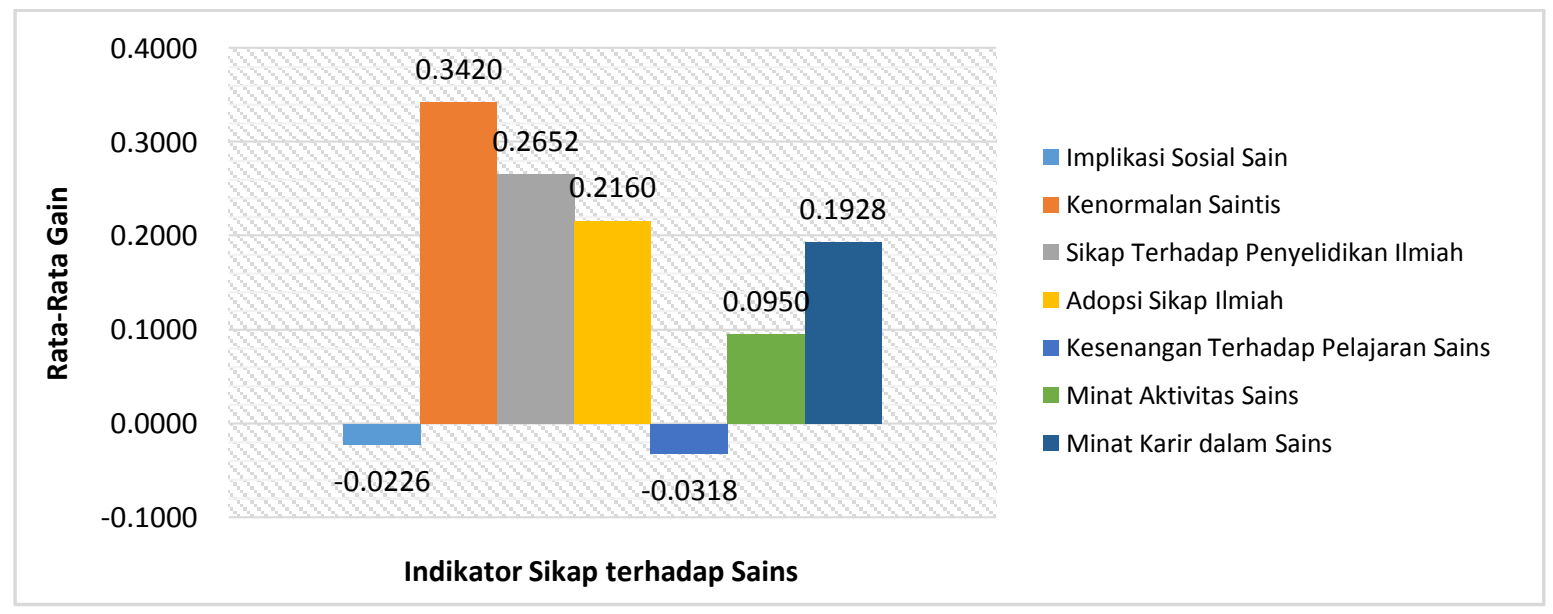

Gambar 1. Chart Rata-Rata Gain tiap IndikatorSikap terhadap Ilmu Pengetahuan (Sains).

Dari sebanyak 7 indikator diketahui bahwa terdapat 5 indikator mengalami peningkatan dan 2 indikator mengalami penurunan (Gambar 1). Indikator yang berada di atas rata-rata data gain dapat dikatakan mengalami peningkatan yang signifikan berdasar selisih hasil pretest dan postest. Sedangkan indikator yang mengalami penurunan bisa dikatakan nilai postest lebih rendah apabila dibandingkan dengan nilai pretest. Indikator yang mengalami peningkatan antara lain; (1) Sikap normal terhadap saintis, (2) Sikap menyukai penyelidikan ilmiah, (3) Adopsi sikap ilmiah, dan (4) Minat karir di bidang sains, dan (5) Minat pada aktivitas sains. Sedangkan indikator yang mengalami penurunan antara lain; (1) Sikap terhadap implikasi sosial sains, dan (2) Sikap senang pada pelajaran sains.

\section{Pembahasan}

Sebagaimana dipaparkan sebelumnya bahwa tujuan penelitian adalah untuk mengetahui perbedaan sikap terhadap sains kelas eksperimen yang mendapat pembelajaran berbasis proyek ilmiah dengan kelas kontrol yang tidak mendapat perlakuan pembelajaran berbasis proyek ilmiah. Maka didapatkan hasil bahwa terdapat perbedaan yang signifikan hasil gain pretest-postestsikap terhadap sains antarasiswa kelas kontrol dan eksperimen (Tabel 3).Perbedaan terlihat dari adanya peningkatan sikap terhadap sains siswa kelas eksperimen yang mendapat pembelajaran berbasis proyek ilmiah dibandingkan siswa yang tidak mendapatkan pembelajaran berbasis proyek ilmiah. Hal ini menunjukkan bahwa pembelajaran berbasis proyek ilmiah mampu meningkatkan sikap positif siswa terhadap sains.

Perkembangan sikap positif siswa terhadap sainsmerupakan salah satu kunci keberhasilan siswa dalam belajar sains. Hal ini bertujuan agar pembelajaran yang diberikan mampu menginspirasi siswa untuk menyukai pelajaran sains dan minat karir di dunia sains (Dosanjh 2015).Pembelajaran berbasis proyek ilmiah yang diberikan kepada siswa merupakan metode pembelajaran yang menerapkan paradigma konstruktivisme yang memandang belajar sebagai proses membangun pengetahuan oleh siswa sendiri, bukan peran pasif pemindahan informasi dari guru kepada siswa. Metode pembelajaran berbasis proyek ilmiah mampu melibatkan siswa dalam investigasi masalah kehidupan sehari-hari hingga siswa termotivasi untuk mencari solusi atas masalah disekitarnya lewat ilmu pengetahuan. Sebagaimana Blumenfeld et al(1991) memaparkan bahwa pembelajaran diawali dengan rumusan masalah, pencarian ide, merancang eksperimen, mengumpulkan data, menarik kesimpulan, hingga menghasilkan sebuah ciptaan artifacts (produk) di akhir pembelajaran 
Peningkatan sikap terhadap sains siswa dalam hasil penelitian ini menunjukkan bahwa pembelajaran berbasis proyek ilmiah mampu menginspirasi siswa untuk melakukan penyelidikan ilmiah dari masalah yang diberikan. Sehingga menambah pemahaman siswa dalam pembelajaran danmenanamkan kebermanfaatan diri di masyarakat. Sebagaimana Willet (1994) memaparkan bahwa hakikat pembelajaran bertujuan untuk meningkatkan sikap, prestasi, dan nilai yang ada pada diri individu sehingga metode pembelajaran yang tepat akan mampu membawa perubahan dalam diri siswa baik secara kognitif, afektif, dan psikomotor.

Salah satu indikator dengan peningkatan tertinggi ditunjukkan dengan meningkatnya sikap normal terhadap saintis pada siswa (Gambar 1). Hal ini menunjukkan bahwa siswa makin memiliki sikap normal terhadapprofesi saintis/ilmuwan yang ditunjukkan melalui apresiasi bahwa saintis adalah orang seperti pada umumnya, bukan orang aneh atau eksentrik seperti yang digambarkan oleh media. Hal ini disebabkan pada proses akhir pembelajaran berbasis proyek ilmiah, siswa ditugaskan untuk menciptakan sebuah proyek ilmiah seperti saintis/ilmuwan. Sebagai contoh, siswa yang akan membuat alat optik berupa proyektor dari bahan sederhana, tentu akan mempelajari hasil temuan dari para saintis yang menemukan lensa optik seperti Anthony van Leuwenhoek. Sehingga melalui kegiatan pembelajaran, siswa makin memiliki sikap normal terhadap profesi saintis/ilmuwan, terlebih lagi menyukai profesi sainstis/ilmuwan.

Berdasarkan Gambar 1, siswa juga makin menyukai kegiatan penyelidikan ilmiah. Menurut Fraser (1981) sikap menyukai kegiatan penyelidikan ilmiah adalah sikap siswa yang menyukai aktivitas eksperimen dan penyelidikan ilmiah sebagai cara mendapatkan informasi tentang dunia. Dalam proses pembelajaran berbasis proyek ilmiah ini, siswa mendapatkan informasi tentang bagaimana alat optik bekerja dalam kehidupan sehari-hari lewat penyelidikan yang dilakukannya. Siswa mampu merakit dan membuat proyektor dari bahan-bahan sederhana. Kegiatan penyelidikan ini mampu membuat siswa belajar melalui pengalamannya sendiri tentang bagaimana hal-hal disekitarnya terbentuk. Bukan hanya dari buku, literatur,penjelasan guru atau para ahli di bidang tersebut. Lewat pembelajaran proyek ini siswa makin menyukai kegiatan penyelidikan ilmiah untuk mengetahui hal-hal yang terjadi di sekitarnya sebagai salah satu indikator sikap positif terhadap ilmu pengetahuan.

Selanjutnya pada tahap akhir pembelajaran berbasis proyek ilmiah, diadakan agenda pameran sains ilmiah. Beberapa negara yang rutin melaksanakan agenda tahunan ini menyebutnya Science Fair. Di Indonesia, belum banyak data atau jejak rekam sekolah yang mengadakan pameran sains ilmiah.Kegiatan pameran ilmiah ini bertujuan agar siswa mampu mempresentasikan hasil ide proyek ilmiah yang telah dibuatnya di hadapan publik. Hal ini merupakan upaya dalam menumbuhkan sikap ilmiah siswa sejak dini. Menurut Munby (1983) menjelaskan bahwa sikap ilmiah merupakan sebuah pola pikir yang menunjukkan karakteristik seorang ilmuwan. Karakteristik tersebut adalah seseorang harus memiliki sikap keingintahuan, kejujuran,rasionalitas, objektivitas,pemikiran terbuka, pemikiran kritis, dan kerendahan hati. Pada saat siswa mempresentasikan proyek ilmiah di hadapan publik, siswa tentu mendapatkan kritik dan masukan. Sangat penting bagi siswa untuk diizinkan menguji dan membagi temuan mereka kepada orang lain. Ini berfungsi sebagai efek penyeimbangan dan motivasi agar siswa beradaptasi terhadap skema baru dan membandingkan pandangannya dengan orang lain (Welch\& Douglas, 2011).Siswa akan belajar untuk bersikap rendah hati, jujur dan berpikir terbuka dalam menerima perkembangan ilmu pengetahuan. Sikap ilmiah yang ditumbuhkan siswa ini merupakan salah satu indikator yang menunjukkan sikap positif terhadap ilmu pengetahuan.

Hasil penelitian ini mendukung studi sebelumnya di Hamza School oleh Faris (2008) bahwa sebanyak 22 siswa dari 25 siswa kelas IXyang telah berpartisipasi dalam kegiatan project based learning, memiliki sikap ilmiah yang tergolong tinggidan memiliki motivasi tinggi untuk merancang penyelidikan kemudian mewujudkannya lewat proyek ilmiah.Faris (2009) juga menambahkan bahwa ini adalah isu terpenting dalam membuat sains di sekolah menjadi menarik, edukatif, dan relevan untuk siswa,yakni dengan meningkatkan peran dan keterlibatan siswa dalam bidang tersebut.

Pameran sains dan pembelajaran berbasis proyek ilmiah ini berpotensi sebagai upaya positif bagi sebuah negara berkembang untuk membuat siswa agar condong dalam bidang sains. Sebab saat ini tiap negara di dunia memiliki tantangan tersendiri dalam membangun generasi saintis. Menjadi penting pada era kemajuan sains dan teknologisaat ini bahwa siswa memahami sains sebagai ilmu yang tidak sekedar mereka baca dari buku. Para pengajar, orangtua dan mentor berkewajiban untuk membawa sains lebih dari apa yang ada dalam buku. Salah satu upaya tersebut adalah dengan mengembangkan pembelajaran yang kreatif dan inovatif guna 
memperlihatkan pada siswa betapa besarnya implikasi sosial sains dalam kehidupan kita. Dengan begitu kita berkesempatan untuk menjadikan sains tumbuh dan hidup dalam pribadi siswa.

\section{SIMPULAN DAN SARAN}

Berdasarkan hasil penelitian yang telah dilakukan dapat disimpulkan bahwa terdapat perbedaan yang signifikan hasil gain pretest-postestsikap terhadap sains antarasiswa kelas eksperimen dan kelas kontrol. Perbedaan terlihat dari adanya peningkatan sikap terhadap sains siswa kelas eksperimen yang mendapat pembelajaran berbasis proyek ilmiah dibandingkan siswa yang tidak mendapatkan pembelajaran berbasis proyek ilmiah. Hal ini menunjukkan bahwa pembelajaran berbasis proyek ilmiah mampu meningkatkan sikap positif siswa terhadap sains. Sebagaimana studi sebelumnya menyebutkan bahwa sikap positif terhadap ilmu pengetahuan berkorelasi positif terhadap prestasi siswa dalam bidang sains. Prestasi siswa dalam sains akan membawa dampak besar dalam segala bidang kehidupan di masa depan. Sebab itu merupakan kunci utama pertumbuhan ekonomi dan kesejahteraan sebuah negara.

Pemerintah sebagai pembuat kebijakan diharapkan untuk melihat kembali ke dalam kurikulum pengajaran bersifat tekstual yang dirasa kurang sesuai dengan minat belajar siswa dalam sains. Perlunya perubahan yang menantang gunamenghadapipersaingan global menuju perkembangan sains dan teknologi abad ke 21.Menanggapi kebijakan terbaru Kementerian Pendidikan dan Kebudayaan (Kemendikbud) RI mengenai full day school pada Sekolah Dasar dan Sekolah Menengah yang bertujuan untuk membangun karakter siswa, metode pembelajaran berbasis proyek ilmiah ini mampu mewujudkan misi pendidikan karakter ilmuwan melalui peningkatan sikap positif siswa terhadap ilmu pengetahuan. Kemendikbud RI bisa memanfaatkan half day school dengan kegiatan proyek dan penyelidikan ilmiah. Hal ini bertujuan membangun karakter ilmuwan siswa guna mendorong kemajuan IPTEK Indonesia di kancah internasional.

\section{UCAPAN TERIMAKASIH}

Ucapan terimakasih peneliti sampaikan kepada Kementerian Riset, Teknologi, dan Pendidikan Tinggi(Kemenristekdikti) Republik Indonesia yang telah memberikan dana penelitian melalui Program Kreativitas Mahasiswa (PKM) 5 Bidang Tahun 2017 Nomor 547/B3.1/KM/2017.

\section{DAFTAR RUJUKAN}

Blumenfeld, P., Soloway, E., Marx, R., Krajcik, J., Guzdial, M., \&Palincsar, A.(1991). Motivating projectbased learning:Sustaining the doing, supporting the learning. Educational Psychologist, Vol. 26, No. (3\&4), pp 369-398.

Dosanjh, M. (2015). Secondary school students' attitude towards life science. International Journal of Multidisciplinary Research and Development, Vol. 2, No. 5, pp 139-142.

Faris, A. (2008). The Impact of PBL on the Students' Attitudes towards Science among NineGraders in Hamza Independent School. Retrieved from ERIC database.

Faris, A.O. (2009). The Impact of Homogeneous vs. Heterogeneous Collaborative LearningGroups in Multicultural Classes on the Achievement and Attitudes of Nine Graderstowards Learning Science. Online submission, retrieved from ERIC database.

Fraser, B. J. (1981). Test of Science-Related Attitude (TOSRA). Hawthorn, Victoria: Australian Council for Educational Research.

Hake, R. (1999). Analyzing Change/Gain Score. American Educational Research Association's Division Measurement and Research Methodology.

Klopfer, L. (1971). Evaluation of Learning in Science. In B. Bloom, J. Hastings, and G.Madaus (Eds.), Handbook of Summative and Formative Evaluation of Student Learning.New York: McGraw-Hill, 559-641.

Munby, H. (1983). Thirty Studies Involving the Scientific Attitude Inventory. What Confidence can we in this Instrument? Journal ofResearch in Science Teaching, Vol. 20, No. 2, pp 141-162.

Narmadha, U \& Chamundeswari S. (2013). Attitude Towards Learning of Science and Academic Achievement in Science Among Students At the Scondary Level. Journal of Sociological Research, Vol. 4, No.2, pp 114-124.

Osborne, J., Shirley, S. \& Sue, C. (2003). Attitudes towards science: A review of the literature and its implications.International Journal of Science Education, Powersearch. Web. 27 Aug. 2016. 
Papanastasiou, E. C., and Zembylas, M. (2004). The effect of attitudes on science achievement: A study conducted among high school pupils in Cyprus. International Review of Education, Vol. 48, No. 6, pp 469-484.

Welch, A \& Douglas H. (2011). The Effect of Robotics Competition on High School Students Attitudes Toward Science. School Science and Mathematics, Vol. 111, No. 8, p 416.

Willett, J. B. (1994). Measuring change more effectively by modeling individualchange over time. In $\mathrm{T}$. Husen, \& T. N. Postlethwaite (Eds.). TheInternational Encyclopedia of Education (2nded.). Pergamon Press, Elmsford,NY. 